\title{
Raspberry Pi based pH Control for Nutrient Film Hydroponic System Ryan Laksmana Singgeta ${ }^{* a}$, Hung-Wei Lin ${ }^{b}$, and Yeong-Hwa Chang ${ }^{a}$ \\ Department of Electrical Engineering, Chang Gung University, Kwei-Shan, Tao-Yuan 333, Taiwan ${ }^{a}$ \\ ${ }^{* a}$ E-mail:ryansinggeta@gmail.com \\ ${ }^{a}$ E-mail:yhchang@mail.cgu.edu.tw \\ Department of Electrical Engineering, Lee-Ming Institute of Technology, New Taipei City 243, Taiwan ${ }^{\mathrm{b}}$ \\ ${ }^{\mathrm{b}}$ E-mail:hwlin@mail.lit.edu.tw
}

\begin{abstract}
This paper presents an automated hydroponic system, where a Raspberry $\mathrm{Pi}$ is used to maintain the pH level in the presence of time-delay. The Ziegler-Nichols method is used for tuning the parameters of the PID controller. Moreover, a Web user interface is developed to control, monitor, and record the $\mathrm{pH}$ level, temperature, and water level. Experimental results illustrate that the required $\mathrm{pH}$ level can be attained by the proposed control scheme.
\end{abstract}

Keyword: Hydroponic, PID controller, Time-delay, Ziegler-Nichols, Web interface.

\section{INTRODUCTION}

Hydroponic is a plant growing method through water culture without the use of any solid substrates [1]. Recently, hydroponic has popularly spiked because the crop quality and productivity has significantly increased [2]. Many methods are provided to build and develop hydroponic systems. According to [3], the conventional method needs more time and manpower to control and monitor hydroponic systems where everything should have manually. The $\mathrm{pH}$ water solution takes a time to read $\mathrm{pH}$ value which is needed to periodically monitor and balance a required value of maintaining a quality of the nutrients solution. Researchers have interested to develop the hydroponic system to be automatically in terms of monitoring and controlling. The automated $\mathrm{pH}$ controller system for hydroponic cultivation has been proposed in [3]-[6]. In [7], the authors provided a smart fuzzy logic control to manage an agriculture production system. In addition, this system control was enhanced with wireless data monitoring platform for data routing and logging, which provides real time data access.

Initially scientists used hydroponics mainly as a research tool to study particular aspects of plant nutrition and root function [1]. In [8], the authors developed a hydroponic system to monitor parameters for the nutrition such as $\mathrm{pH}$ and EC (electrical conductivity). This study focuses on developing the hydroponic system especially for the plant nutrition which is using mineral nutrient solutions in water. The water quality is essential for hydroponics. The $\mathrm{pH}$ level in water affects the absorption of certain nutrients by the roots.

Therefore, $\mathrm{pH}$ level is considered to be one of the most important determining factors of crop yield and quality [2]. The $\mathrm{pH}$ value is a parameter that measures the acidity or alkalinity of a solution. This value indicates the relationship between the concentration of free ions $\mathrm{H}^{+}$and $\mathrm{OH}^{-}$solution with ranges 0 to 14 [2]. In general, a range of irrigation solution pH levels between 5.6 and 6.8 is required [1]. Accordingly, this paper aims to maintain the $\mathrm{pH}$ level in hydroponic system. In this study, the mixing process between pure water and $\mathrm{pH}$ decreasing is distributed by a DC motor in the box with a delay time. The variations of the $\mathrm{pH}$ value in the box are not directly measured by the $\mathrm{pH}$ sensor. Therefore, the action of the DC motor as a output and $\mathrm{pH}$ sensor as a input in control system will lead to delays and error actions. The paper [9] proposed a fuzzyPID control method to adjust the $\mathrm{pH}$ value which has time delay in acid and alkali neutral reaction process. The other technique, in [10], the paper proposed reset control of an industrial in-line $\mathrm{pH}$ process with significant time delay and gain uncertainties. Basically, a time delay will tend to destabilize a closed-loop system and hence makes it much more difficult to control [11]. It is a challenge how to control the $\mathrm{pH}$ value with consider the delay/dead time in hydroponic system.

In recent years, the PID controller is one of main control tools being used to solve the industrial problem, particularly those of the process industries. The PID control module is a building block which provides the regulation and disturbance rejection for single loop, cascade, multi-loop, multi-input, and multi-output scheme. For tuning the PID coefficients, the Ziegler-Nichols open loop method is used in this study. The Ziegler-Nichols method is heuristic rule for experimental design. Furthermore, an embedded system is developed to integrate the temperature sensor LM35, pH sensor, SRF08 range sensor, the DC motor and AC motors as actuators, Raspberry $\mathrm{Pi}$ as a master control, and PIC18F4525 microcontroller as a slave for control of the hydroponic system. Also, to enhance the hydroponic system, a web interface for monitoring the data access is provided, which includes $\mathrm{pH}$ value, temperature, and water level through wireless communication. As a whole, this paper aims to maintain the quality of the water in hydroponic system with controlling the $\mathrm{pH}$ level by using a PID controller for time-delay system and design a web interface and database to monitor the data access in directly. 


\section{SYSTEM DESCRIPTION}

\subsection{Hydroponic System Design}

In general, hydroponic technique consists of six types: wick, deep water culture, ebb and flow, drip, nutrient film technique (NFT) and aeroponic [4]. In [12], the authors proposed the aquaponic cultivation technique that utilized the excretion from fish as a nutrient for the plants. In this paper the hydroponic is designed based on nutrient film technique and shown in Fig. 1. Nutrient film technique (NFT) is a hydroponic technique wherein a very shallow stream of water containing all the dissolved nutrients required for plant growth. The first step, the structure of the hydroponic system is designed by using the SolidWorks software [13]. This system is built by some main materials such as pipes with size 2.5 inches, irons, and rubber tubes. For the details of the size is shown in Fig. 1.

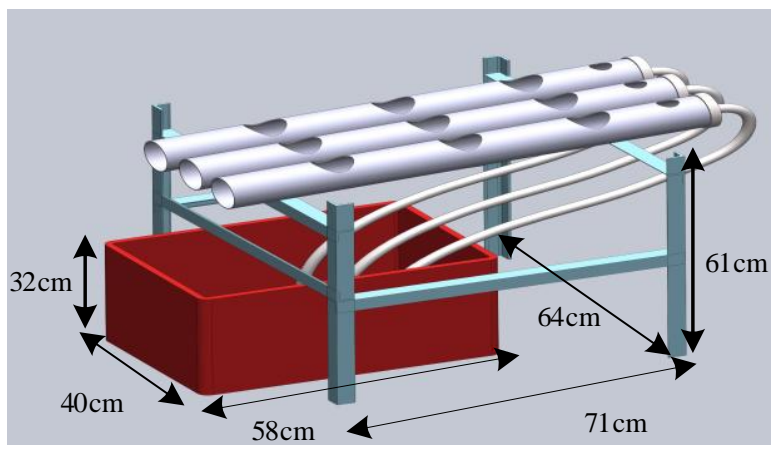

Fig. 1 Scheme Diagram of the Hydroponic System

Moreover, an embedded system is built to integrate the components of input as the sensors, output as the actuators and PIC18F4525 microcontroller as slave, and Raspberry Pi as master of the process. System configuration for the hardware is shown in Fig. 2. The system is being monitored and controlled by Raspberry $\mathrm{Pi}$, which continuously receives data of $\mathrm{pH}$ sensor, and temperature sensor through $\mathrm{I}^{2} \mathrm{C}$ (Inter-Integrated Circuit), protocol from the circuit microcontroller PIC18f4525. $\mathrm{I}^{2} \mathrm{C}$ uses serial data line (SDA) and serial clock (SDC) for communication between the master and slave. The PIC18f4525 microcontroller has a feature 10-bit Analog to Digital (A/D) converter, this feature is used to convert the data of $\mathrm{pH}$ sensor and temperature sensor from analog to digital and the signals are processed to become a $\mathrm{pH}$ value and temperature in the Celsius degree. Also, through $\mathrm{I}^{2} \mathrm{C}$ protocol, the Raspberry Pi can give the command to control the DC motor which is connect with PIC18F4525 microcontroller by using PWM (pulse width modulation) and can control AC motors on or off. To control the input voltage of DC motor, this paper use the PWM 8bits (values between $0-255$ ) to set the duty cycle. The relationship between the value of bit and output voltage is shown in Table 1.

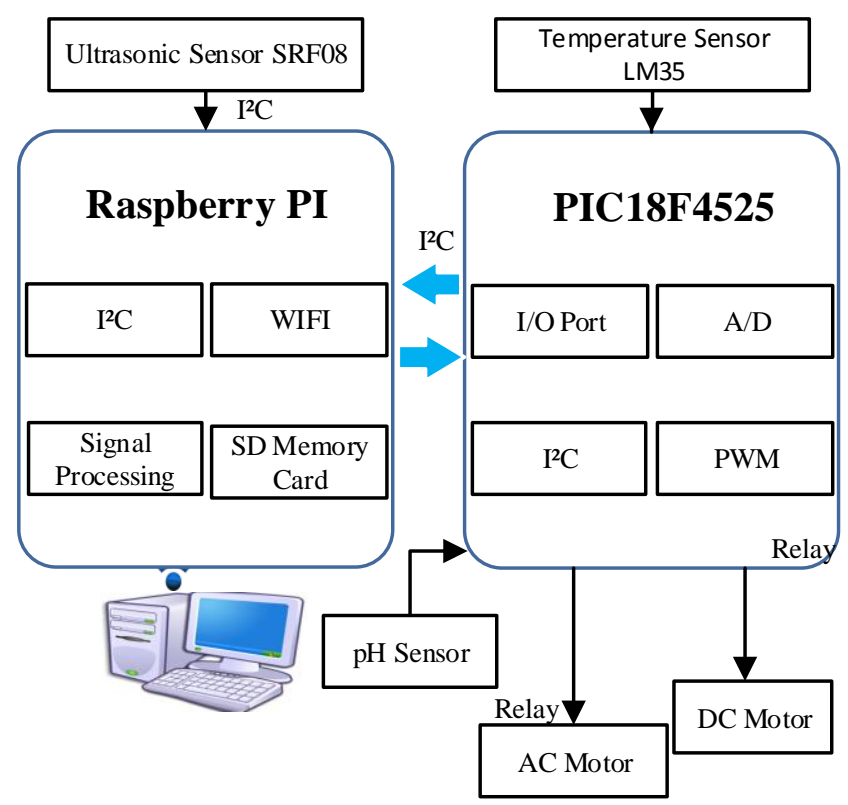

Fig. 2 Block Diagram of Hydroponic System

TABLE 1 : PWM (8-bits) and input Voltage DC Motor [volt]

\begin{tabular}{|c|c|c|c|}
\hline 0 & 10 & 20 & 30 \\
\hline 12.07 & 11.11 & 10.51 & 10.07 \\
\hline 40 & 50 & 60 & 70 \\
\hline 9.63 & 9.21 & 8.8 & 8.41 \\
\hline 80 & 90 & 100 & 110 \\
\hline 8.01 & 7.62 & 7.23 & 6.86 \\
\hline 120 & 130 & 140 & 150 \\
\hline 6.46 & 6.1 & 5.69 & 5.3 \\
\hline
\end{tabular}

\subsection{Raspberry Pi}

The Raspberry Pi is a small card sized single board computer and developed by the Raspberry Pi Foundation [14]. The Raspberry Pi hardware has evolved through several versions that feature variations in memory capacity and peripheral device support. In this study we use Raspberry Pi model B, which is shown in Fig. 3. The features in this board are listed in Table 2. By using the WiFi device which is connect with USB port in Raspberry $\mathrm{Pi}$, the data can be monitored, controlled, and recorded in PC (personal computer). The PC can access a remote the Raspberry Pi by using the SSH (secure shell), which is a network protocol to provide administrators with a secure way. Moreover, the data from the sensors and actuators is recorded and collected in database server. The software XAMPP is used in this study which is contain the AMP (Apache, MySQL, PHP) to design a web interface between users and server. 


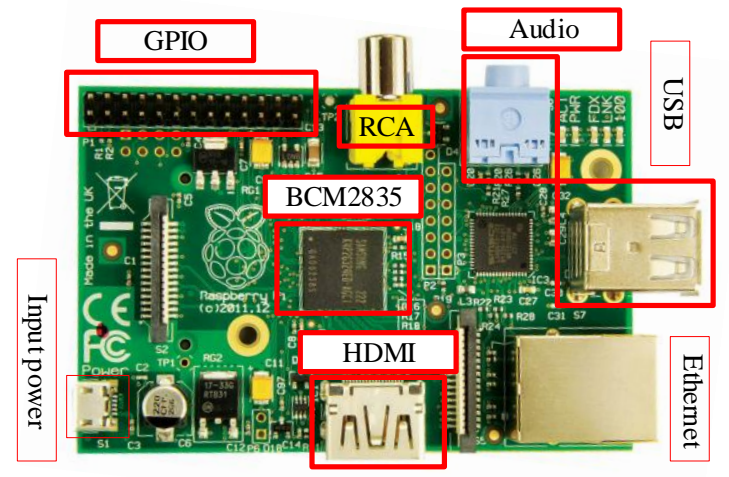

Fig. 3 Raspberry Pi Module

TABLE 2 : The Features of Raspberry Pi Model B

\begin{tabular}{|l|l|}
\hline System On Chip & Broadcom BCM2835 \\
\hline CPU model & ARM1176JZF-S core \\
\hline Clock rate & $700 \mathrm{Mhz}$ \\
\hline RAM & $512 \mathrm{MByte}$ \\
\hline GPIO & 17 Pins as Inputs and Outputs \\
\hline USB PORT & 2 \\
\hline Video Output & HDMI, RCA \\
\hline Input Power & 5 V/via MicroUSB or GPIO \\
\hline Storage & Micro SD \\
\hline Communication modes & $\mathrm{I}^{2} \mathrm{C}$, UART, SPI, WiFi, LAN \\
\hline
\end{tabular}

\subsection{PIC18F4525 Microcontroller}

The PIC18f4525 microcontroller is the one series of the PIC 18 family with width data memory is 8-bit. PIC18 family of low cost and high performance. The features of this microcontroller is show in Table 3.

TABLE 3 : The Features of PIC18f4525 Microcontroller

\begin{tabular}{|l|l|}
\hline Operating Frequency & DC-40 Mhz \\
\hline Memory Flash (bytes) & $48 \mathrm{~K}$ \\
\hline I/O Ports and Pins & $\mathrm{A}, \mathrm{B}, \mathrm{C}, \mathrm{D}, \mathrm{E}$ (36 Pins) \\
\hline Input power & $4.2-5.5 \mathrm{~V}$ \\
\hline $\begin{array}{l}\text { 10-Bit Analog-to- } \\
\text { Digital Module }\end{array}$ & 13 input Channels \\
\hline Timers & 4 \\
\hline Communication modes & $\mathrm{I}^{2} \mathrm{C}, \mathrm{UART}, \mathrm{SPI}$ \\
\hline
\end{tabular}

The PCB board is designed to integrate some electronic components and devices with PIC18f4525, as shown in Fig. 4. Therefore, the microcontroller will be easy and flexible to control and access the relays and the other components without cables. Also, the power supply can be share to every components efficiently. This microcontroller is programmed by using $\mathrm{C}$ language. For the code editing, programming and debugging, the MPLAB ICD 2 software is used. MPLAB is a proprietary freeware integrated development environment for the development of embedded application on PIC and it is developed by microchip technology Inc.

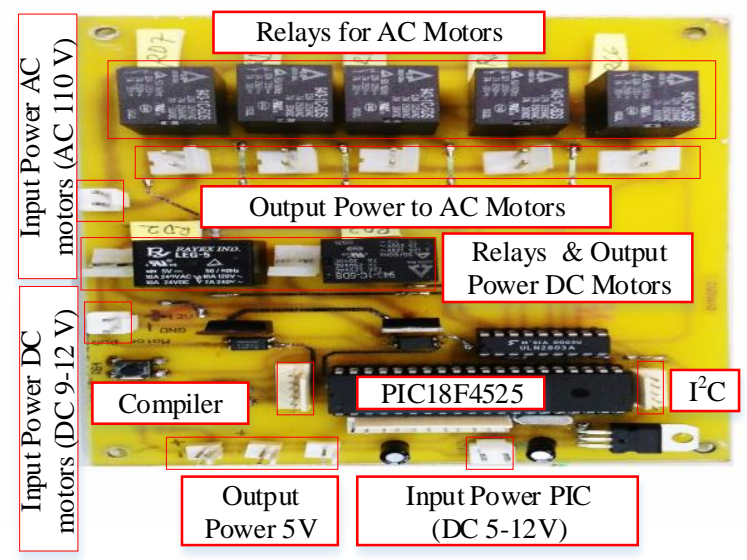

Fig. 4 PIC18F4525 Microcontroller Board

\section{4. pH Sensor SEN016}

This hydroponic system is equipped by $\mathrm{pH}$ sensor SEN0161 to measure the water quality Fig. 5. The pH sensor SEN0161 is a analog pH meter which is it can measure the $\mathrm{pH}$ value with range (0-14). This sensor is made up of a probe which is contained two electrodes with bulbs. The bulbs made from a specific glass. For the specification of this sensor is shown in Table 4.

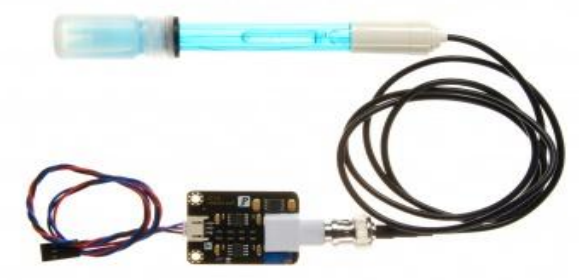

Fig. 5 pH Sensor SEN016

TABLE 4 : Specification of pH sensor SEN016

\begin{tabular}{|l|l|}
\hline Input Power & $5 \mathrm{~V}$ \\
\hline Size & $43 \mathrm{~mm} \times 32 \mathrm{~mm}$ \\
\hline Accuracy & $0.1 \mathrm{pH}$ \\
\hline Input power & $4.2-5.5 \mathrm{~V}$ \\
\hline $\mathrm{pH}$ measuring & $0-14$ \\
\hline $\begin{array}{l}\text { Response } \\
\text { time }\end{array}$ & 2 second \\
\hline Interface & $\mathrm{pH} 2.0$ (3 foot patch) \\
\hline
\end{tabular}

The pH electrode is connected to the BNC (Bayonet NeilConcelman) connector on the $\mathrm{pH}$ meter board. This sensor is connected to the analog pin in PIC18F4525 microcontroller. The output signal from this sensor is processed in the microcontroller by using $\mathrm{A} / \mathrm{D}$ converter. This signal is 
calibrated into the $\mathrm{pH}$ value by using linier regression method. The linear regression attempts to model the relationship between two variables by fitting a linear equation to observed data. The simple formula for regression line is :

$$
Y=a+b x
$$

where is $Y$ is predicted score, $\mathrm{b}$ is the slope of the line, and $\mathrm{a}$ is the $Y$ intercept. For two variables are output $\mathrm{pH}$ sensor and buffer solution. A buffer solution is resists changes in the $\mathrm{pH}$ of the solution. Therefore, this buffer solution as a way to calibrate the $\mathrm{pH}$ sensor. The 3 buffer solutions is used for calibration such as, acidic buffer solution which has a $\mathrm{pH} 4$, neutral $\mathrm{pH} 7$, and alkaline buffers solution which has a pH 10 Fig. 6.

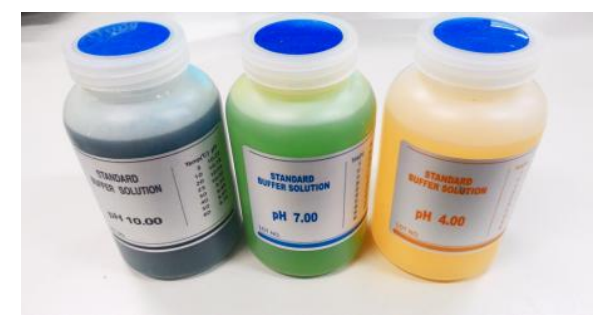

Fig. 6 Buffer Solutions

The relationship between output voltage $\mathrm{pH}$ sensor and buffer solution are shown in Fig. 6. By using the formula (2) which is computed with statistical software, it can get the equation for the line Y.

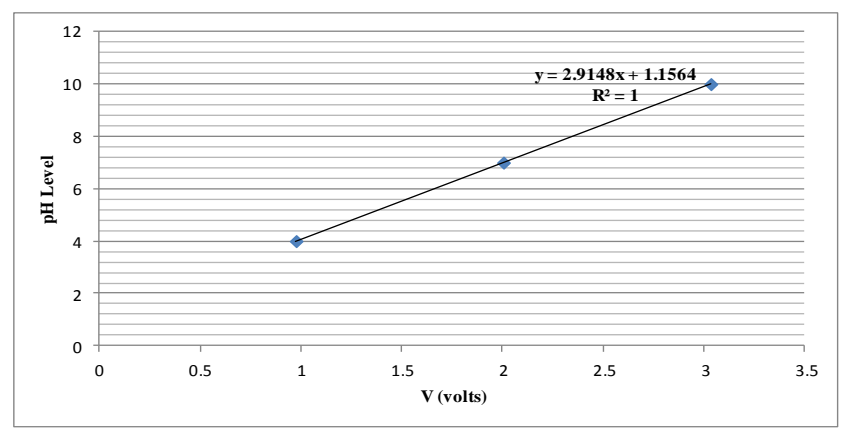

Fig. 6 Calibration Curve of the pH Sensor

\subsection{Temperature Sensor (LM35)}

The water temperature is one of the important environmental factors in hydroponic system, especially in $\mathrm{pH}$ controlling. The water temperature is one of the significant effect on $\mathrm{pH}$ measurement. Therefore, the hydroponic system is equipped with IC (integrated circuit) LM35 to measure the temperature sensor is shown in Fig. 7.

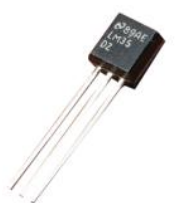

Fig. 7 IC LM35 Temperature Sensor
This sensor is connected with a analog pin in PIC18f4525 microcontroller. The output signal is converted from analog to digital by using $\mathrm{A} / \mathrm{D}$ converter. This signal is calibrated with analog thermometer by using linier regression method (1). The equation for the line $Y$ and the relationship between output voltage and analog thermometer is shown in Fig. 8.

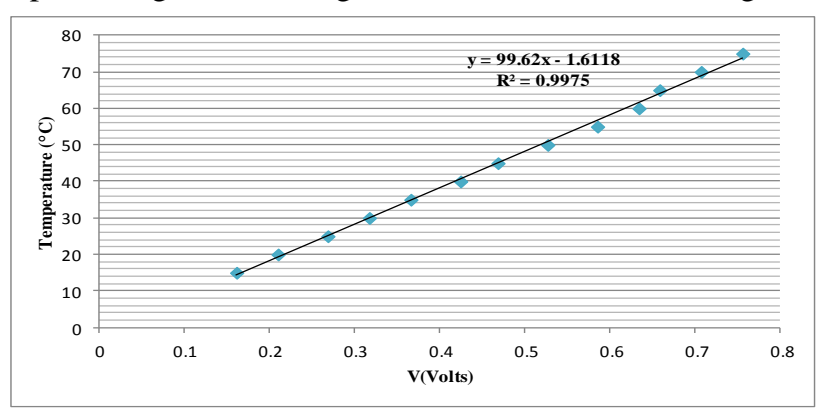

Fig. 8 Calibration Curve of the Temperature Sensor

\subsection{SRF08 Ultrasonic Sensor}

In this study, SRF08 ultrasonic sensor is used to measure the water level in the box which is show in Fig. 9. The sound wave reflection time is converted into the range between SRF08 sensor and water. For the specification of this sensor is shown in Table 5.

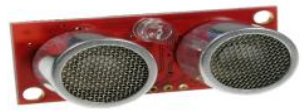

Fig. 9 SRF08 Ultrasonic Sensor

TABLE 5 : Specification of SRF08 Ultrasonic Sensor

\begin{tabular}{|l|l|}
\hline Input Power & $5 \mathrm{~V}$ \\
\hline Range & $3 \mathrm{~cm}-600 \mathrm{~cm}$ \\
\hline Frequency & $40 \mathrm{KHz}$ \\
\hline Resolution & $1 \mathrm{~cm}$ \\
\hline Connection & $\mathrm{I}^{2} \mathrm{C}$ \\
\hline
\end{tabular}

\section{CONTROL SYSTEM DESIGN}

\subsection{PID Control System}

The proportional- integral- derivative- (PID) controller is the main control law used in this study wherein this control is the simplest control system method. The control signal is thus a sum of three terms: the P-, I-, and D- controllers. The controller parameters are proportional gain $K_{p}$, integral time $T_{i}$, and derivative time $T_{d}$. The formula of a PID controller is shown in equation (2).

$$
u(t)=K\left[e(t)+\frac{1}{T_{i}}\right]_{0}^{t} e(t) d t+T_{d} \frac{d}{d y} e(t)
$$

where $u(t)$ is the control signal, and $e(t)$ is the error in equation (3). The set point (SP) in this study is defined by $\mathrm{pH}$ value, and for the process variable (PV) from the working PID control system is measured by $\mathrm{pH}$ sensor. 
Proceedings of the $24^{\text {th }}$ Conference on Automation Technology National Chung Hsing University, Taichung, 4 5 November, 2016

$$
e=S P-P V
$$

The PID control scheme is shown in Fig. 10, in which the set point (SP) of $\mathrm{pH}$ level is set in $5.5-6.5$. The value of error will send and be multiplied with PID parameters and then the results of the controller are used to control the DC motors by using pulse width modulation (PWM).

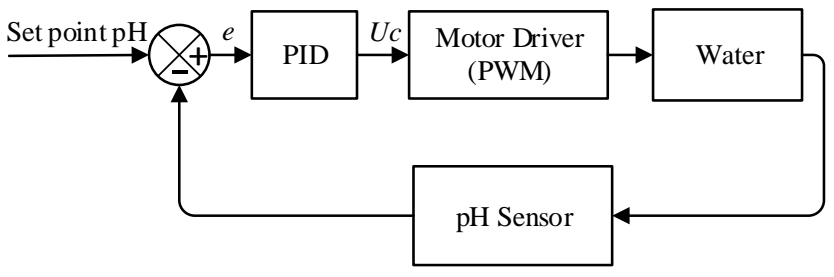

Fig. 10 PID Control Scheme

\subsection{Z-N Tuning Method based pH Control}

In this paper, the Ziegler-Nichols (Z-N) method is adopted to determine the PID coefficients, $K_{p}, T_{i}$ and $T_{d}$. The flowchart of $\mathrm{pH}$ control system is shown in Fig. 11. The first action, the ph is measured by $\mathrm{pH}$ sensor in PIC18F4525 microcontroller which is mentioned in section 2 , then the data from $\mathrm{pH}$ sensor is processed in Raspberry Pi to calculate the error and compute the desired a DC motor output by calculating the proportional, integral, and derivative responses with error. If the $\mathrm{pH}$ level is larger than 6.5 the data will be process and calculate in PID control, otherwise if not the motor action is stopped. In this study the sampling time to do the action and record the data is defined 5 second.

\section{EXPERIMENTAL RESULTS}

\subsection{Real Design of NFT Hydroponic System}

In this real design of NFT Hydroponic System is equipped with some components are PIC18F4525 microcontroller board, Raspberry Pi, sensors and actuators as a mentioned in section 2 . Also, the 3 holes for every pipe is made where is the pot putting some plants which is shown in Fig. 12.

\subsection{Open Loop Test}

The process reaction curve is identified by doing an open loop step test of the process. For open loop test, the $\mathrm{pH}$ decreasing is defined as a input which is distributed from DC motor. The input voltage of DC motor is 9,63 volt with delay 8.32 second. The $\mathrm{pH}$ decreasing is made by mixing between 300 gram citric acid powder with $500 \mathrm{ml}$ of water in the bottle. Fig. 13 shows the measurement of $\mathrm{pH}$ open loop system during 0 to 1800 seconds. By using the ZieglerNichols open loop method, it have analyzed and gotten the coefficients of $K_{p}=0.85, T_{i}=50$, and $T_{d}=12.5$ which is shown in Fig. 14.

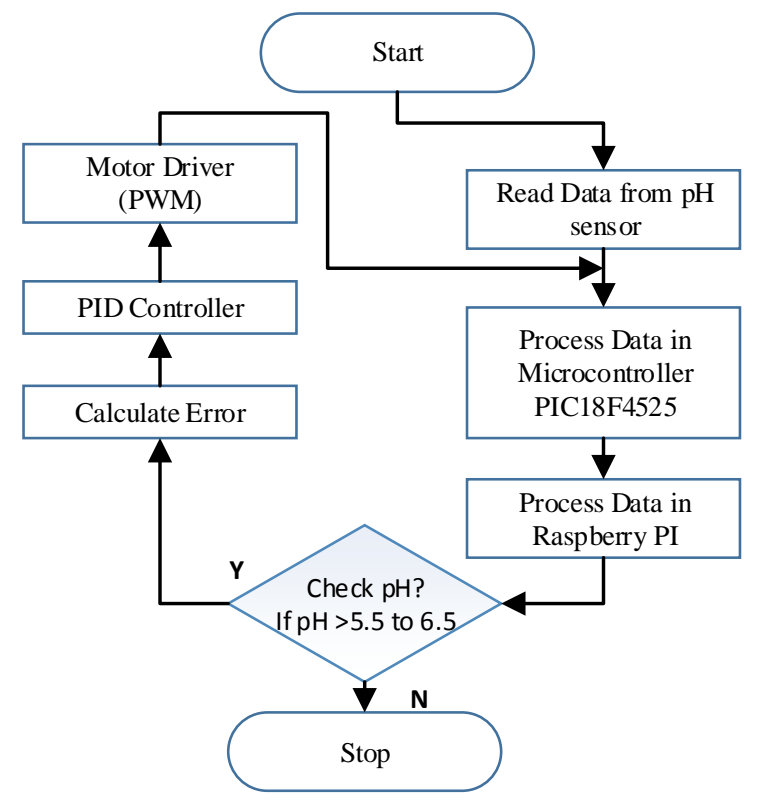

Fig. 11 Flowchart of $\mathrm{pH}$ control

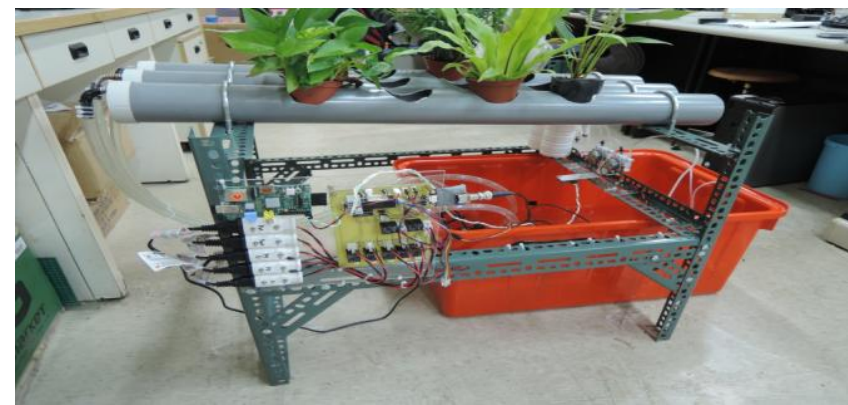

Fig. 12 Nutrient Film Technique Hydroponic System

\subsection{Test for PID control}

Experimental results show that the required range of $\mathrm{pH}$ level from 5.5 - 6.5 is achieved, which contributes to enhance the plant growth and shown in Fig. 15. The PID control with sampling time 5 seconds is better than the less than the time for control this system which have time delay.

\subsection{Web Interface}

The web interface developed in this paper is shown in Fig. 16. Through the login interface, users can fill the username and password. On other hand, the set-up interface contains start/end date, measured items ( $\mathrm{pH}$ value, temperature, water level, and PWM), and interval time to be shows in graph. Fig. 16 shows the $\mathrm{pH}$ value with the date in 16/08/2016 and interval time 5 second. Moreover, there is a table containing the recording of dates, $\mathrm{pH}$ level, temperature, $\mathrm{PWM}$ and pumps. 


\section{CONCLUSION}

In this paper, an automated hydroponic system was implemented, where the control kernel was performed based on Raspberry Pi. Based on the Ziegler-Nichols method, the PID coefficients can be obtained and the desired $\mathrm{pH}$ value control can be achieved. To make the data recording and control monitoring more efficiently, a web based database is developed. In the future, intelligent control methods may be worth of investigating to improve the control performance.

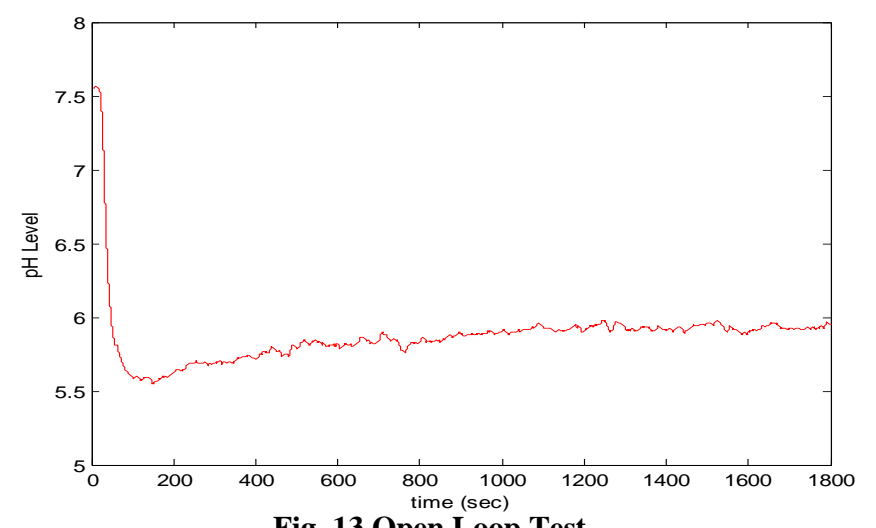

Fig. 13 Open Loop Test

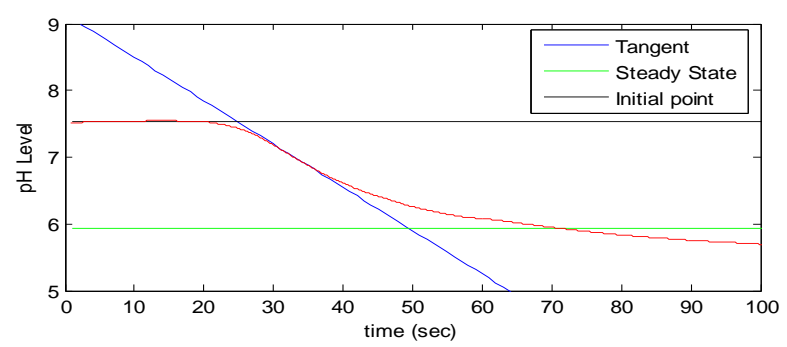

Fig. 14 Open Loop Tuning

\section{REFERENCES}

[1] R. Michael and J. H. Lieth, Soilless Culture Theory and Practice, Amsterdam: Elsevier Science, 2008.

[2] T. Asao, Hydroponics - A Standard Methodology for Plant Biological Researches, InTech, Japan, 2012.

[3] M. F. Saaid, N. A. M. Yahya, M. Z. H Noor, and M.S.A Megat Ali, "A development of an automatic microcontroller system for deep water culture (DWC)," in Proc. IEEE Int. Colloq. Signal processing and its Application, pp. 328-332, 2013.

[4] M. F. Saaid, A. Sanuddin, M. Ali, and M. S. A. I. M. Yassin, "Automated $\mathrm{pH}$ controller system for hydroponic cultivation," in Proc. IEEE Conf. Comput. Appl. Ind. Electron, pp. 186190, 2015.

[5] V. Aparna, "Development of automated ph monitoring \& control system through usb data acquisition," in IEEE Power India Int. Conf. (PIICON), pp. 1-6, 2014.

[6] L. Melvix, and C. Sridevi, "Design of efficient hydroponic nutrient solution control system using soft computing based solution grading", in Proc IEEE Conf. Computation of Power, Energy, Inform. and Commun., pp. 148-154, 2014.
[7] M. Azaza, C. Tanougast, E. Fabrizio, and A. Mami, "Smart greenhouse fuzzy logic based control system enhanced with wireless data monitoring," ISA Trans., vol. 61, pp. 297-307, Mar. 2016.

[8] L. A. Velázquez, M. A. Hernández, M. León, and R. B. Domínguez, "First advances on the development of a hydroponic System for cherry tomato culture," in Proc IEEE Conf. Comput. Sci. and Automat. Control, pp. 155-159, 2013.

[9] H. Xie Shi, "Research about fuzzy-PID control method of $\mathrm{pH}$ value in chemical industry process," in Proc IEEE Conf. Elect. and Control Eng., pp. 1554-1557, 2010.

[10] C. Joaquin and B. Alfonso, "Reset control of an industrial inline pH process," IEEE Trans. Control Syst. and Technol., vol. 20, no. 4, pp. 1100-1106, June. 2011.

[11] J. A. Michael and M. H. Moradi, PID Control New Identification and Design Methods, London: Springer-Verlag, 2005.

[12] M. F. Saaid, N. A. M. Yahya, M. Z. H Noor, and M.S.A Megat Ali, "Automated indoor aquaponic cultivation technique," in Proc. IEEE Int. Conf. Syst. Eng. Technol., pp. 285-289, 2013

[13] O. Godfrey, Computer-Aided Engineering Design with SolidWorks, Imperial College Press: London, UK, 2013.

[14] G. Warren, Mastering The Raspberry PI, : SpringerLink, 2014.

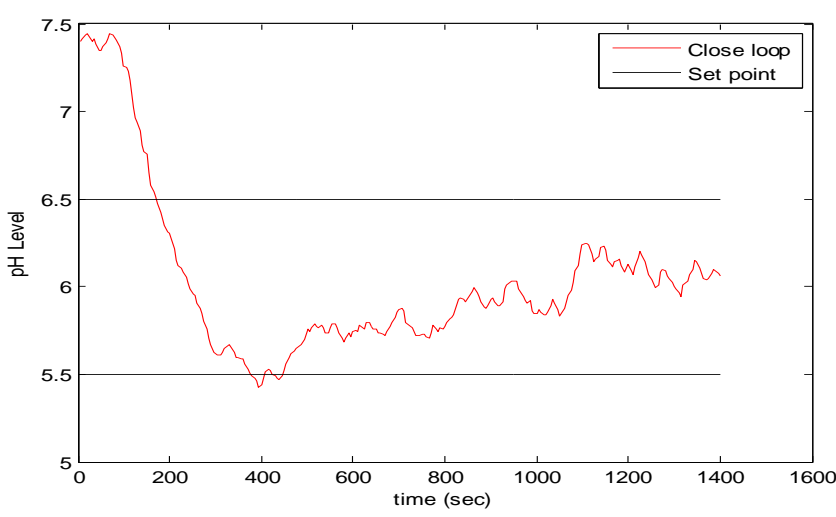

Fig.15 PID Control with sampling time 5 seconds

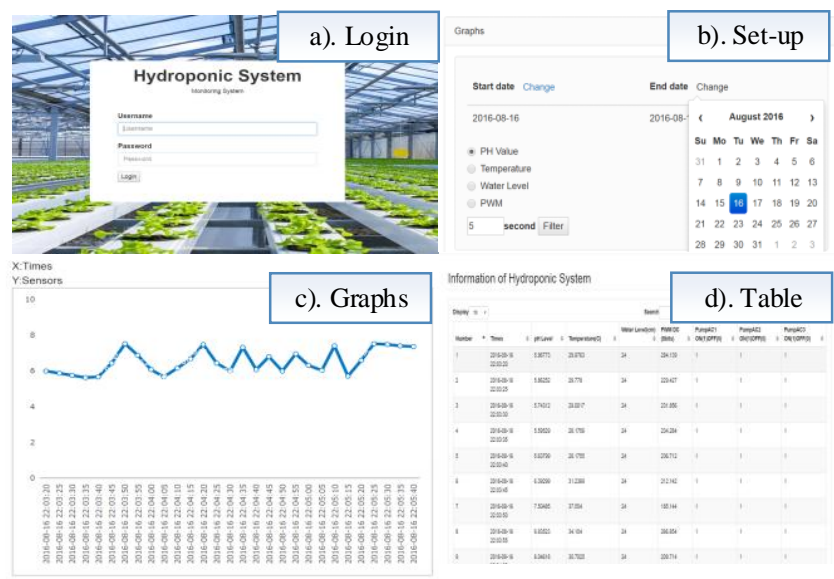

Fig. 16 Web Design : a. Login , b. Set-up, c. Graphs, d. Table 